\title{
Study of Asymmetric Failure Law and Support for Large Embedded Depth Roadway Driving along the Roof in Inclined Coal Seam
}

\author{
Cheng Guoqiang, Yan Mingju, Zhu Hongli, Yu Haifeng \\ (College of mining and Safety Engineering Shandong University of Science and \\ Technology, Shandong Qingdao 266590)
}

\begin{abstract}
The roadway driving along the roof for large embedded depth often had irregular failure in inclined coal seam at one coalmine, in order to analyze the failure law of roadway, this paper adopted the method of elastic-plastic analysis and numerical simulation to study the stress, plastic zone and deformation of roadway in inclined coal seam when the embedded depth of roadway is $1000 \mathrm{~m}$. it can be concluded that the stress peak position and plastic region of high side are greater than the low side, the low side in the upper and high side in the lower part are the large area of roadway deformation. Based on the damage characteristics, this article puts forward the support scheme, which is combined support of bolt-mesh-anchor and reinforce the support to the high side with the anchorage cable. It obtains a good supporting effect and provides a new way for support design of large embedded depth roadway in inclined coal seam.
\end{abstract}

Keywords: inclined coal seam, large embedded depth, Elastic-Plastic analysis, numerical simulation analysis, asymmetric deformation, combined support.

\section{Introduction}

The roadway driving along the roof in inclined coal seam often leaded to little support effect when used supporting types as rectangular roadway. Researching the cause, The angle between the direction of gravity and bedding direction became smaller because of the existence of coal seams dip, the gravity increased along bedding direction, this caused the exhibit with asymmetry deformation and failure of surrounding rock. It was more difficult to maintain the stability of the roadway with the greater depth and angle. So it has very important practical significance that reveals the damage rule, feature and designs to corresponding support of roadway driving along roof for large embedded depth in inclined coal seam. 
2.Elastic-plastic surrounding rock asymmetrical deformation in inclined coal seam roadway

The stress state would change with the roadway excavating, surrounding rock divided into elastic and plastic zone. Existing elastic-plastic theory had a good explanation to elastic and plastic regions of round and oval roadway. For the rectangular roadway, it did not have suitable mechanical model of elastic-plastic because of the complexity calculation. To be able to explain damage state of surrounding rock in rectangular roadway using the mechanical model of elastic-plastic, Many scholars made the rectangular roadway as circumcircle of diameter $l$, and it simplified the complexity of calculating rectangular roadway by calculating a circular elastic-plastic situation ${ }^{[7]}$. For example Fig 1.

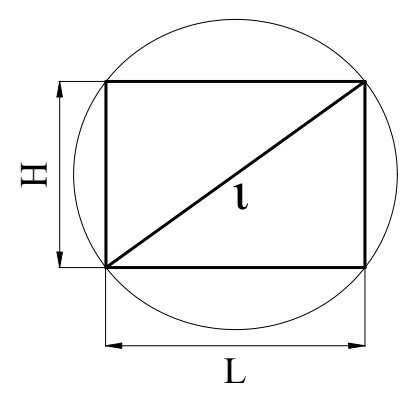

Fig.1 Equivalent sectional

Getting plastic zone of surrounding rock in rectangular roadway approximately by calculating the circular cross-section, although it had an error using method of section equivalent with elastic-plastic mechanics analysis compared to the actual destruction state of the rectangular roadway, it could reflect the failure situation of surrounding rock in rectangular roadway.

The section was ladder driving along the roof in inclined seam coal roadway. To simplify the calculation, using the method of section equivalent analog rectangular roadway, it was equivalent to the circular that the diameter is $l$. Considering the different height of two sides, selected the long diagonal as the equivalent circle diameter to analyze the plastic zone of high side and selected the short diagonal as equivalent circle diameter to analyze plastic zone of low side, For example Fig 2. Fig.3.

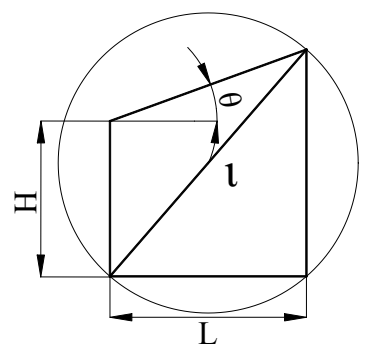

Fig.2 Equivalent section to analyze the plastic zone of high side

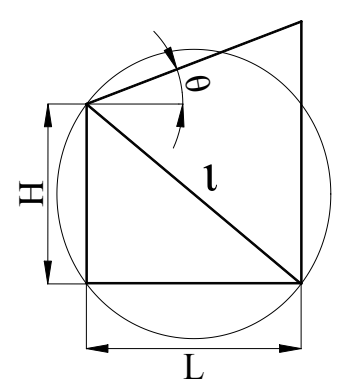

Fig.3 Equivalent section to analyze the plastic zone of low side

Concluded the radius of surrounding rock 
between elastic and plastic zone:

$$
\begin{aligned}
& R_{P}=\frac{\sqrt{L^{2}+H^{2}}}{2}\left[\frac{2 p_{0}(\varepsilon-1)+2 \sigma_{c}}{\sigma_{c}(\varepsilon+1)}\right]^{\frac{1}{\varepsilon-1}}= \\
& \frac{\sqrt{L^{2}+H^{2}}}{2}\left[\frac{\left(p_{0}+c \cot \varphi\right)(1-\sin \varphi)}{c \cot \varphi}\right]^{\frac{1-\sin \varphi}{2 \sin \varphi}}
\end{aligned}
$$

Equivalent circle radius of high side:

$$
r_{a}=\frac{\sqrt{(L \tan \theta+H)^{2}+L^{2}}}{2}
$$

Equivalent circle radius of low side:

$$
r_{a}=\frac{\sqrt{L^{2}+H^{2}}}{2}
$$

Plastic zone of two sides in ladder roadway:

$$
R_{1}=R_{p}-\frac{L}{2}
$$

According to the above formula, selecting $c=1.1 \mathrm{Mpa}, \varphi=29^{\circ}$, width is 4 meter and low side is 3 meter of roadway, it could be concluded the plastic zone of two sides. For example Fig 4.

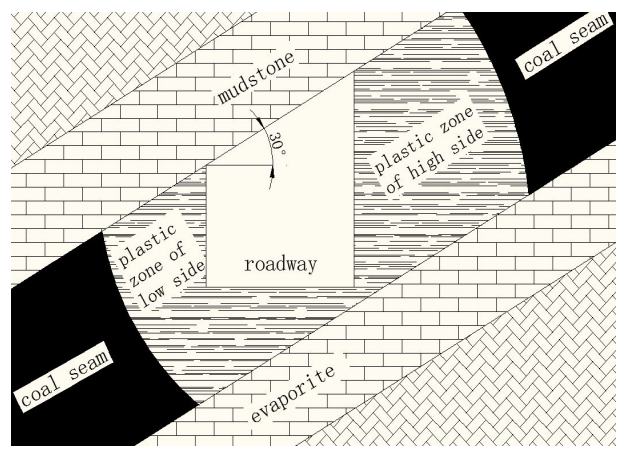

Fig.4 The plastic zone distribution schematic diagram of the buried $1000 \mathrm{~m}$ in excavation roadway' $\mathrm{s}$ two sides

The failure characteristics of driving along the roof in inclined seam coal roadway was different to horizontal, Based on the method of elastic-plastic with section equivalent, it derived that the plastic zone in the high side was larger than the low side, so the degree of damage in high side was more than the low side, it revealed the mechanism of asymmetric failure in inclined coal seam roadway.

\section{Failure law of roadway using numerical simulation analysis in inclined coal seam}

In order to get failure character of the surrounding rock in roadway whose depth was $1000 \mathrm{~m}$, the numerical simulation method was adopted. Making the coal seam dip $30^{\circ}$, roadway width 4 meter, low side 3 meter, lateral pressure coefficient 1 as the research object, it could be concluded the law of deformation failure through the analysis of surrounding rock stress and displacement.

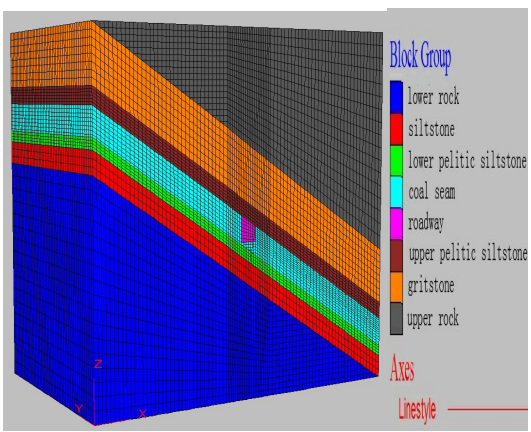

Fig.5 Numerical simulation model 


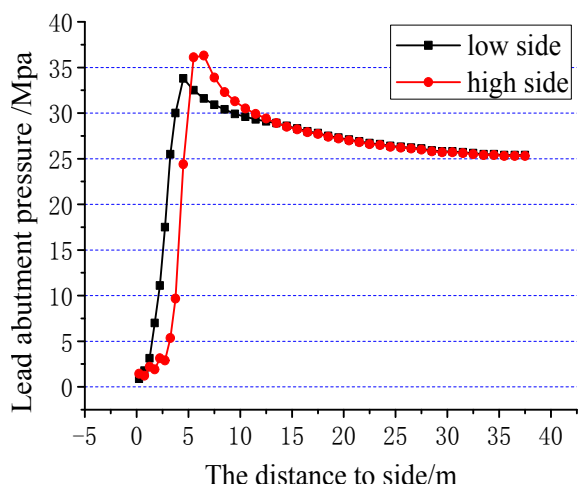

Fig.6 The vertical stress distribution

of two sides

When the depth was 1 kilometer, the vertical stress of two sides had increase at first then decrease and tended to the rock stress last with the increase of distance to the side. The peak of stress in high side was $36.3 \mathrm{Mpa}$, the peak of stress in low side was $33.8 \mathrm{Mpa}$, So the peak stress in high side was larger than the low side. the position of peak stress in high side was 6.5 meter, the position of peak stress in low side was 4.5 meter, So the position of peak stress in high side was larger than the low side.

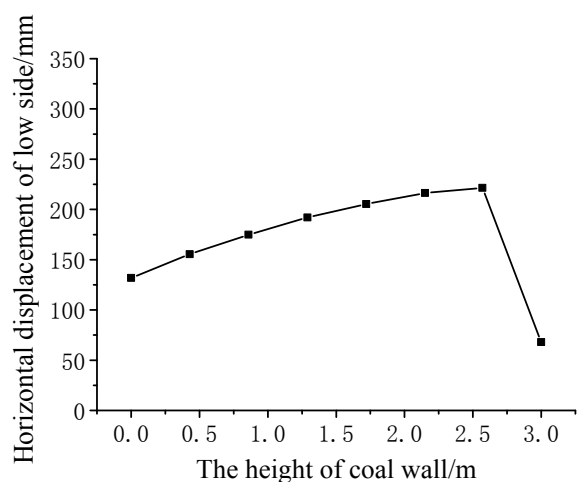

Fig.7 Horizontal displacement of coal wall in low side

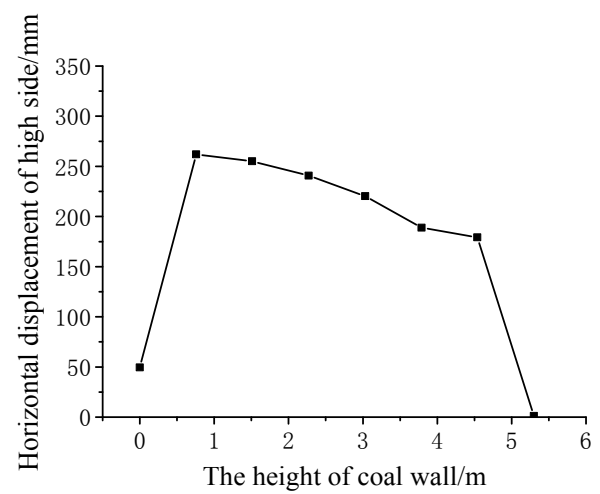

Fig. 8 Horizontal displacement of coal wall in high side

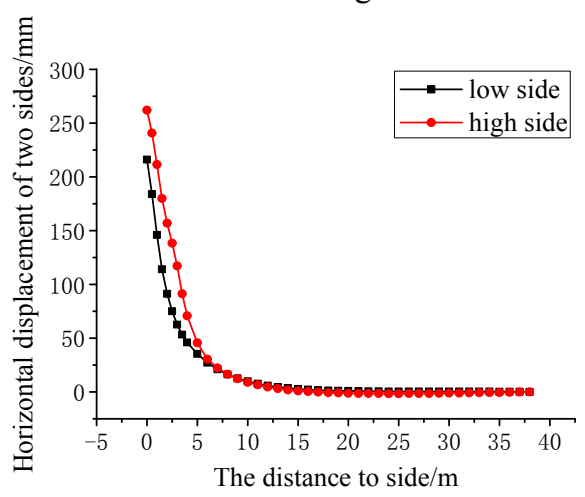

Fig.9 Horizontal displacement of surrounding rock in two sides

As could be seen from the curve of horizontal displacement in two sides, when the depth reached $1000 \mathrm{~m}$, the low side in the upper and the high side in the lower part were the large deformation area of roadway. The horizontal displacement in high side was larger than the low side. The horizontal displacement of surrounding rock in two sides reduced gradually with the increase of distance to the side, The range was 2.5 meter that horizontal displacement of surrounding rock in low side was greater than $70 \mathrm{~mm}$, the range was 4 meter that horizontal displacement of surrounding rock in high side was greater than $70 \mathrm{~mm}$, So 
surrounding rock in high side had a large disturbance range. In inclusion, the low side in the upper and high side in the lower part are large deformation, the horizontal displacement of surrounding rock in high side was larger than the low side.

\section{Design of roadway support}

\subsection{Section design of roadway support}

Elevation of belt crossheading was -868.9 meter -992.5 meter in one coalmine, coal seam thickness was $1.6 \sim 5.5 \mathrm{~m}$, coal seam dip angle was $14^{\circ} \sim 37^{\circ}$, average $30^{\circ}$, Construction was driving along the roof. The section was irregular rectangular that net width of roadway was 4.0 meter, the net height of low side was 3.0 meter, effective net section area of roadway was $18.0 \mathrm{~m}^{2}$. During initial construction, the deformation of high side in roadway was large, more serious, the high side of roadway was failure, it leaded to rework multiple and high labor cost of manual.

Considering the roadway was coal roadway, surrounding rock was relatively soft and easily broken, low side in the upper and the high side in the lower were the part of large deformation; the high side had larger bare range and was loose easily, only used anchor was difficult to control deformation. another used the bolt net support, although it could control the crushing coal, the failure of the bolt would result in failure of the entire support structure, what was more, face mining effected to roadway, it was difficult to maintain the stability of roadway. So in order to control deformation of surrounding rock roadway effectively, this paper putted forward support scheme which was combined support of bolt-mesh-anchor and reinforced the support to the high side with the anchorage cable in inclined coal seam roadway.

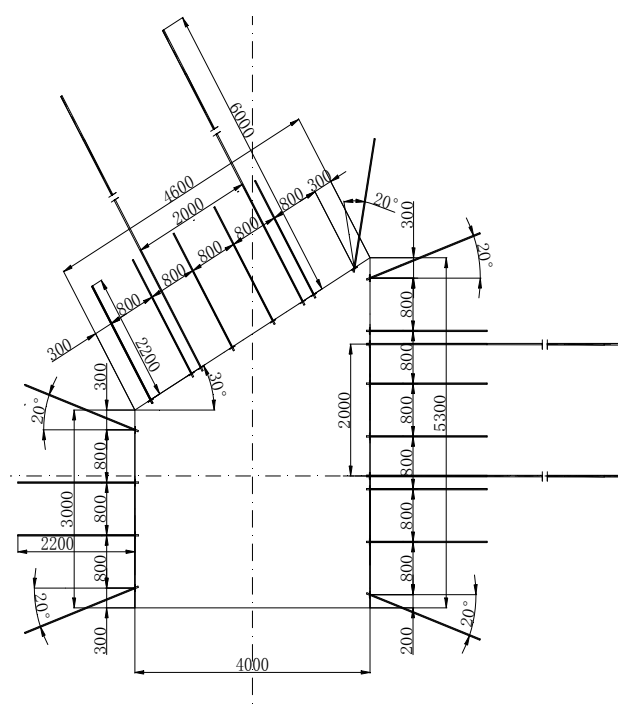

Fig.10 Support section

\subsection{Numerical simulation analysis of support effect}

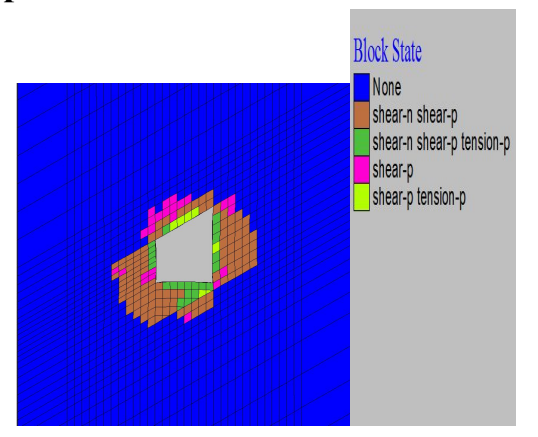

Fig.11 The plastic zone distribution with strengthen support to high side 


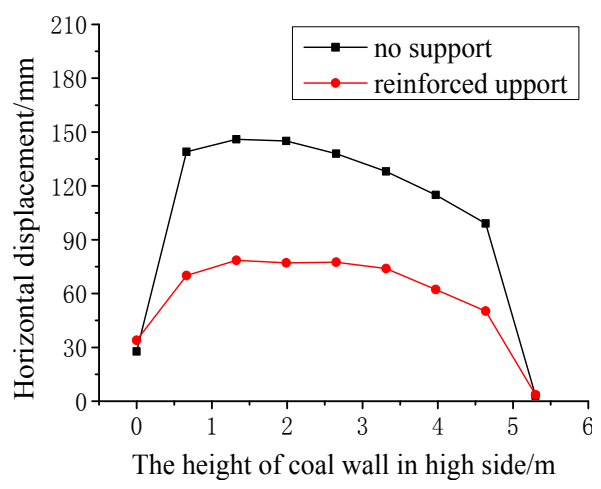

Fig.12 Horizontal displacement of high side with roadway support in pre and post

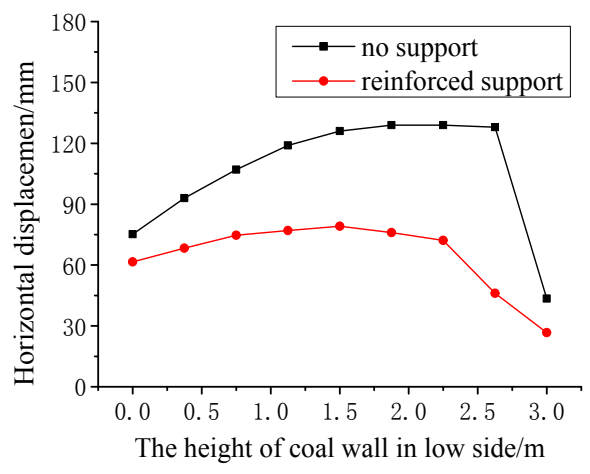

Fig.4.13 Horizontal displacement of low side with roadway support in pre and post

It could be seen the plastic zone of surrounding rock in support pre and post during driving, the plastic zone in two sides was respectively 5.5 meter and 3.5 meter before support, but the plastic zone in two sides was respectively 3 meter and 2.9 meter after reinforcing support. The horizontal displacement was respectively $146 \mathrm{~mm}, 128 \mathrm{~mm}$ in high and low side before support, then the horizontal displacement was respectively $78 \mathrm{~mm}$, $77 \mathrm{~mm}$ in high and low side after reinforcing support, the horizontal displacement in two sides has significant change, it was small in two sides. So the support scheme which was combined support of bolt-mesh-anchor and reinforced the support to the high side with the anchorage cable could control horizontal displacement in high side of roadway effectively, it ensured the stability of roadway.

\section{Data analysis of on-line measuring}

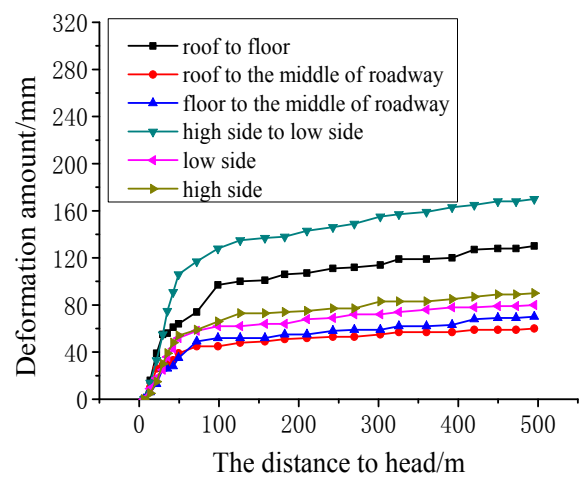

Fig.14 Displacement curve of the roadway surface

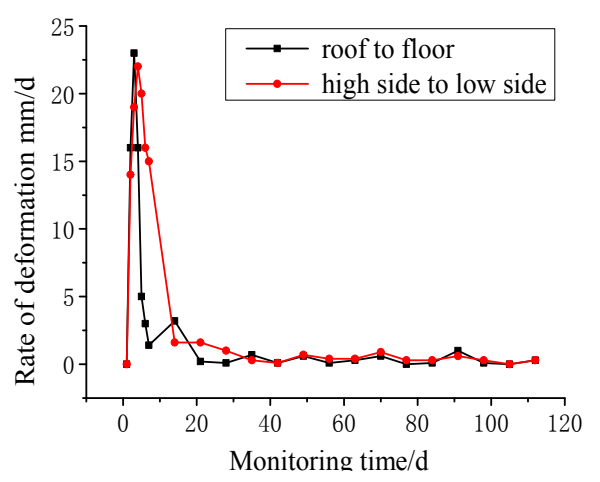

Fig.15 Deformation rate curves of measuring point

It could be seen from the above curves, the maximum relative displacement of roof and floor was $130 \mathrm{~mm}$, Among that, the maximum roof subsidence was $60 \mathrm{~mm}$ and the maximum floor heave was $70 \mathrm{~mm}$, it tended to stability when the distance was $90 \mathrm{~m}$ to the head; the maximum relative displacement of two sides was $170 \mathrm{~mm}$, the maximum displacement of 
low side was $80 \mathrm{~mm}$ and the maximum displacement of high side was $80 \mathrm{~mm}$, it tended to stability when the distance was $100 \mathrm{~m}$ to the head, the deformation of roadway was small. Rate of roadway deformation was large after driving 15 days, the maximum rate of roof and floor attained to $23 \mathrm{~mm} / \mathrm{d}$, the maximum rate of two sides attained to $22 \mathrm{~mm} / \mathrm{d}, 15$ days later, it tended to 0 . So as a result of the analysis of surface displacement measured data, it ensured the request of roadway stability to use the support scheme which was combined support of bolt-mesh-anchor and reinforced the support to the high side with the anchorage cable.

\section{Conclusion}

Aiming at the phenomenon of irregular failure in two sides of roadway driving along the roof for large embedded depth in inclined coal seam, the method of making the rectangular roadway as circumcircle is proposed, the plastic zone of high side and low side have been study with the elastic-plastic theory, it can be concluded that the plastic zone of surrounding rock in the high side is larger than the low side. As a result that numerical simulation analysis for large embedded depth roadway in inclined coal seam, it can be concluded that the low side in the upper and high side in the lower part are the deformation large area of roadway. According to the characteristics of damage deformation for large embedded depth roadway in inclined coal seam, this article puts forward support scheme, which is combined support of bolt-mesh-anchor and reinforces the support to the high side with the anchorage cable. By numerical simulation and field measured, the results show that the support scheme can control deformation of high side in the coal seam roadway effectively, and improve the stability of roadway.

\section{References}

[1]Sun Xiaoming, Zhang Guofeng, Cai Feng . asymmetric deformation mechanism within inclined rock strata induced by excavation in deep roadway and its controlling countermeasures[J] . Chinese Journal of Rock Mechanics and Engineering, 2009, 6 (6): 1137-1143. [2]Zhang Mingjian, GAO Jinhai, WEI Shiyi . similarity simulation study of failure characteristics of surrounding rocks of tilted strata roadway $[\mathrm{J}]$. Chinese Journal of Rock Mechanics and Engineering, 2010, (increase1) (5): 3259-3264.

[3]Li Yanbin, Yang Yongkang, Su Xuegui . study on the stability of surrounding rocks of a coal roadway in different depth[J] . journal of TaiYuan university of technology, 2011, 6 (11): 603-606.

[4]Zhang Bei, CAO Shenggen, Wang Lianguo. deformation failure mechanism and support measurements in roadway of steeply inclined coal seam[J]. Journal of Mining \& Safety Engineering, 2011, 2: 214-219. 
[5]Wu Zhanrui, Qi Taiyue, Zhong Lin. numerical simulation and model test of surrounding rock deformation of deep roadway $[\mathrm{J}]$. China Safety Science Journal, 2012, 2 (2): 44-49.

[6]Wu Hai, Zhang Nong, Wang Weijun. simulation and control of deep roadway inclined rock strata[J]. Journal of Hunan University of Science \& Technology( Natural Science Edition), 2013, 1 (3): 6-11.

[7]Shen Mingrong, Chen Jianfeng. Rock Mechanics[M] . ShangHai , TongJi University press, 2006.

deformation characteristics within 